\title{
Pious Life of Elderly People in Ampara District of Sri Lanka
}

\author{
S. M. Ayoob ${ }^{1}$ \\ ${ }^{1}$ Head/ Department of Sociology, Senior Lecturer in Sociology, South Eastern University of Sri Lanka, Sri Lanka \\ Correspondence: S. M. Ayoob, Department of Sociology, South Eastern University of Sri Lanka, Sri Lanka. \\ E-mail: ayoobsm@seu.ac.lk; ayoobsm2004@gmail.com
}

Received: September 19, 2019

doi:10.5539/jpl.v12n4p145
Accepted: October 28, 2019 Online Published: November 28, 2019

URL: https://doi.org/10.5539/jpl.v12n4p145

\begin{abstract}
Religion has continued to occupy a very important part in human life from time immemorial. Almost all the followers of the various religions have belief in the existence of God. It helps humankind to find solace in God while religious instructions assist them to guide their lives in the right way without being tempted to engage in sinful activities. The followers of religion are mostly the elderly people rather than the younger generation in many societies. Elders' more extensive life experience, education and worldly wisdom enable them to lead a more pious life than the youngsters, who still have much to learn. The elders try to set an example to the youngsters in order to persuade them also to be religious. The aim of the study is to find out the roles the elders play when engaging in religious activities during the ageing period and to explore the reasons for the high level of piousness among them. In this study, both qualitative and quantitative methods such as questionnaire survey, interviews and focus group discussions were employed as data collection techniques. The findings indicate that listening to religious sermons, participating in religious celebrations, performing administrative and leadership roles, doing social work, going on spiritual journeys and visiting the sick and praying for them are the notable religious activities undertaken by the elderly people. Being very pious can lead to religious experiences, prevent feelings of isolation and loneliness, provide opportunities for social interaction, grant peace of mind, help pass the time, increase the physical strength and improve mental health by reducing anxiety and aimless behaviour. These are some of the major reasons for the high level of piousness observed among the elderly people who were the subjects of this study.
\end{abstract}

Keywords: elderly people, pious life, religion

\section{Introduction}

Religion is universal, permanent, pervasive and of perpetual interest to humans. Human beings not only have biological, economic and social needs, but they also have a need for religion. Man has a quest for religion that causes him to become restless if he is unable to fulfil that need even if all his other physical needs are satisfied fully. Hence, the biblical saying, 'man does not live by bread alone'. It is also said that man from the earliest times has been incurably religious. However, even though religion is a universal phenomenon, it is understood and practiced differently by different people. Scholars have defined religion in numerous ways. Emile Durkheim defined religion as a "unified system of beliefs and practices relative to sacred things, that is to say, things set apart and forbidden." American anthropologist Edward Sapir said, "The essence of religion consists of man's unceasing attempt to discover a road to spiritual serenity across the perplexities and dangers of daily life." Maclver and Page have defined religion as follows: "Religion as we understand the term implies a relationship not merely between man and man but also between man and some higher power." According to Ogburn, "Religion is an attitude towards superhuman powers." Max Muller defines religion as "A mental faculty or disposition, which enables man to apprehend the infinite" (Rao, 2007).

The human life cycle could be divided into different stages, such as childhood, adolescence, adulthood and old age. Categorical definitions of terms like old, elderly, aged and ageing are not straightforward and not universally applicable. Traditionally, the term 'elderly' refers to people who have attained a certain chronological age. The perception of 'elderly' varies from country to country and culture to culture. Ageing is the process of growing older. While it is a universal biological process, among humans ageing also has important social and cultural dimensions. The term 'age' incorporates different concepts such as 'chronological age' (how old a person is according to the calendar), 'biological age' (the condition of a person's physical state in biological terms), 'functional age' (defined on the basis of functions he can perform in his daily life), and 'social age' 
(social expectations about how people should behave or appear as they grow older) (Tarani Chandola, 2013). Scholars have also defined the word 'ageing' from other perspectives. Becker defined ageing in the broadest sense, as those changes occurring in an individual because of the passage of time (Sharma, 2007). Tibbitts (1960) says that ageing may best be defined as the survival of a growing number of people who have completed the traditional adult roles of making a living and childrearing. The optimum and minimum age fixed for treating a person as 'aged' varies from country to country. In the Western world, age 65 is generally considered as the demarcation age, whilst in most of the developing world that age is 60. In Sri Lanka anyone aged 60 and above is considered as a 'Senior Citizen' (Siddhisena, 2004). It is widely accepted that chronological age is a poor indicator of functional ability. The World Health Organisation (WHO) recognizes all persons who are 60 years and above as the elderly or aged (Nasreen, 2009).

Religion plays an important part in human life. People who actively engage in religious worship tend to be happier than religiously inactive members of society. All people who believe in God follow their own religious faith and they engage in different religious activities according to their age category. In this respect, religion plays a major role in the life of elderly people. The level of religious participation of elderly people is much higher than that of people in all other age categories. The elderly religious community accounts for the largest number of persons who participate in religious activities and it is this group that engages most in voluntary social activity (Kaplan \& Berkman, 2019).

Generally, elderly people after they retire from work are likely to remain at home and lead a very relaxed lifestyle. Theories on elderly people try to elaborate regarding the behaviour and social interaction of people after they become old. Disengagement theory of Cumming and Henry emphasized that the withdrawal from social interaction that occurs in old age was a natural, universal and inevitable process. Society distances itself because of the need to fit younger people into the spaces once occupied by the older people who are no longer considered as useful or dependable as they were before they grew old. The elderly, on the other hand, choose to keep their distance as they become aware of their diminishing capacities and the short time left for them before death. The distancing is a prelude to the ultimate act of disengagement, which occurs upon the death of the old person. In marked contrast to this, the activity theory of Havighurst diametrically differs from the disengagement theory by positing that the older population is able to stay involved and active and that doing so, is in fact, the most advantageous approach to adopt by those who are growing old. The only thing separating old age and middle age is the biological process, not societal wants and needs (Chadha, 1997).

The foregoing two theories on ageing described the roles played and activities undertaken by elders during the ageing period from different perspectives. The elderly population is presented with two diametrically opposed options: one is withdrawal from social interaction and connected activities and the other is continuous engagement and involvement in what they have been doing already. Involvement in religious activities and pursuit of pious life and related involvements were highly visible among the elderly people in the study area.

Several studies have been conducted in Sri Lanka on the ageing population from different perspectives. Siddhisena (2004) carried out a study of elders in Sri Lanka that highlighted their population and growth rate; Silva in year 2004 conducted a study that focused on family support to elders. Amarabandu (2004) studied about the social security mechanism for elders; Wijeratne (2004) focused on laws enacted to protect the rights of elders in Sri Lanka; Nimal Sanderatne conducted a research on the socio-economic implications of ageing in 2004; and Rohini Seneviratne (2004) worked on health and availability of healthcare for elders in Sri Lanka, and in the year 2008, Abeykoon and Ruwanthi carried out a research on emerging social issues of the ageing population in Sri Lanka. Many of these studies focused on health, socio-economic challenges and issues, security, laws and the rights and implications of the ageing population in Sri Lanka. Despite all this work, studies focusing on the involvement of the ageing population in religious activities and detailed description of the pious life of elders has been lacking in Sri Lanka.

In this regard, this study was conducted to identify the roles played by elders in religious activities and the reasons for the high level of piousness among the elderly people. This was done in view of the lack of existing studies on the involvement of elderly people in religious activities in Sri Lanka.

\section{Materials and Methods}

Ampara is one of the 25 administrative districts of Sri Lanka. Ampara district includes the four electoral divisions of Pottuvil, Sammanthurai, Ampara and Kalmunai, under which are 20 Secretariat Divisions, 503 Grama Niladhari Divisions and 614 villages. Civic services are provided to all these places by 02 Municipal Councils, 01 Urban Council and 17 Pradeshiya Sabhas. Sinhalese, Tamils and Muslims are the three major communities living in the Ampara district. The district is mainly agriculture based but there is potential for 
industrial development (Source: District Secretariat, Ampara, 2018).

The researcher selected Amparai district of Sri Lanka for the purpose of the present research study. It should be noted that Amparai district has in all 20 Divisional Secretariats, of which 05 Divisional Secretariat areas were selected by simple random sampling method for conducting the study. They are Addalaichenai, Sammanthurai, Kalmunai Tamil, Akkaraipattu and Pottuvil.

This study was performed using both qualitative and quantitative research methods. The qualitative and quantitative data were collected using primary and secondary sources. The secondary data were collected through Divisional Secretariat handbooks, NGO records, official records, published books, journal articles, online archives and other relevant documents. The primary data were collected through a questionnaire survey from 388 elderly respondents who were chosen based on simple random sampling methods. 06 Key Informant Interviews and 03 Focus Group Discussions (FGDs) were also used to gather data.

The scientific sample size was calculated by making use of the mathematical formula of Taro Yamane (2005). The calculation is as follows.

$$
\text { Sample size }=\frac{N}{1+N(e)^{2}}
$$

Here $\mathrm{N}=13422$ (Total number of elders in the study area)

$\mathrm{e}=$ Confidence level $=0.05$

$$
\begin{gathered}
\text { So sample size for the study }=\frac{13422}{1+13422 \times(0.05)^{2}} \\
=388
\end{gathered}
$$

Each selected divisional secretariat is treated as a stratum. Proportionate sample size is adopted to select the sample from each stratum. In another words, since the total sample size is fixed at 388 , the sample size for each Divisional Secretariat has been obtained proportionately. In this strict sense, the random sampling with proportional allocation has been adopted (refer Table 01). The respondents were selected at random using the table of random numbers.

Table 1. Selection of sample size

\begin{tabular}{lcc}
\hline Selected Divisional Secretariats & Total number of elders & Selected sample size \\
\hline Addalaichenai & 2576 & $(2576 \times 388) / 13422=74$ \\
Sammanthurai & 3639 & $(3639 \times 388) / 13422=105$ \\
Kalmunai Tamil & 2498 & $(2498 \times 388) / 13422=72$ \\
Akkaraipattu & 2858 & $(2858 \times 388) / 13422=83$ \\
Pottuvil & 1851 & $(1851 \times 388) / 13422=54$ \\
\hline Total & $\mathbf{1 3 4 2 2}$ & $\mathbf{3 8 8}$
\end{tabular}

(Source: District Secretariat, Ampara, 2015)

\section{Results and Discussion}

\subsection{Roles of Elders in Religious Activities}

It is mostly the elders who have the knowledge related to culture and religion in societies. They serve as the role models for the younger generation so that they too will follow the culture and perform the religious ceremonies. They transmit the culture, values, customs, folklores, mores, taboos and norms of the society to the younger generation as well as they could. They are the museum and the encyclopedia to the research students who have to collect data. The elders play many roles in the village life. They take part as leaders during the time of ceremonies and festivities. For instance, they are able to answer any question relating to cultural habits and practices because they are knowledgeable. They can teach about all aspects of the rituals and rites of ceremonies to the younger members of society to enable the smooth continuation of the traditions and religious practices. In many cultures, the elders are responsible for passing down the traditions orally, by teaching and instructing younger members. By relating stories, myths, legends, and singing devotional songs, they keep their heritage and 
history alive.

The religious roles played by the elders in the study area are presented in Table 02 .

Table 2. Roles of elders in religious activities

\begin{tabular}{llll}
\hline Religious Roles and Activities & Male (\%) & Female (\%) & Total (\%) \\
\hline Religious Sermons & 6.0 & 6.5 & 12.5 \\
Religious Celebrations & 6.0 & 17.0 & 23.0 \\
Administrative and Leadership Roles & 8.2 & 1.3 & 9.5 \\
Social Work & 13.0 & 8.0 & 21.0 \\
Spiritual Journey & 7.6 & 6.4 & 14.0 \\
\hline Visiting the Sick and Praying & 8.2 & 11.8 & 20.0 \\
Total & $\mathbf{4 9}$ & $\mathbf{5 1}$ & $\mathbf{1 0 0}$ \\
\hline
\end{tabular}

$\mathrm{n}=388$

Source: Survey data, 2018

There are two communities living in the study area following three major religions, viz. Islam, Hinduism and Christianity. Table 02 indicates that $12.5 \%$ of the elders conduct religious sermons during which they explain the scriptures in order to enlighten the community members on the correct way to perform religious rites. The elders provide detailed explanations based on the religious holy books such as Al-Quran, Bible and Bhagavath Geethai. Moreover, the elders teach the youngsters about worshiping patterns and the ways of their own religion, through delivering discourses on theological concepts, religious doctrines and beliefs. In particular, the elders in the study area teach morals to the youngsters, such as the difference between right and wrong, speaking the truth in all circumstances, being trustworthy and refraining from cheating. Further, the elders are active in performing Bhajan among the Hindu community while Islamic principles and dogma are taught by the Matharasa teachers, Dayees, Hazraths and Imams in the Muslim Community. The elders under the guidance of the mosque perform these religious roles. The contributions of males $(6.0 \%)$ and females $(6.5 \%)$ in this activity are approximately the same. The FGDs reveal the following: "We find that there are adults who do not know how to perform religious rites and lack a clear understanding of religious scriptures. This ignorance allows them to engage in antisocial activities that create tension within their own and outside communities. In this respect, we try to achieve conditions of social harmony by educating the ignorant members of the community to adhere to religious teachings to foster understanding and tolerance towards other religious communities. We do this by explaining to them the true meaning of religious coexistence." The elders play a crucial part in teaching religious principles to adults and children. Through these religious sermons, elders help the people to understand the reality of the world and essence of religion. The youngsters are guided to acquire a good understanding of their own religion to prevent them from following the path of religious extremism and ethnocentrism and even engaging in conflict with other religious communities.

The Temple, Mosque and Church generally entrust the organisation of traditional religious celebrations to the elders (23.0\%). The conduct of Thiruvilas (Temple celebrations) in Hindu areas, Kanthoori in Muslim areas, and so on are effectively coordinated with the help of the elders in a community. The elders possess a wealth of experience in conducting such celebrations. They organise traditional games and related activities during the Sinhala and Tamil New Year that falls in April, Draupadi Amman temple celebration etc. and religious get-togethers among Muslims in a particular mosque (Local name - Kadakkarapalli) in the study area. Elders willingly participate in the religious celebrations and enjoy themselves, which does much to relieve their tension and stress. The participation of elders in religious celebrations has beneficial effects as this prevents irregularities and ensures that the proceedings are conducted in an orderly fashion. The elders from the Tamil and Muslim communities involve themselves deeply in organizing religious celebrations and events. The FGDs reveal that the involvement of the elders is a very satisfying experience for them and that it rejuvenates their mind and body. In addition, it provides the opportunity to meet old friends from different places. Time passes happily for them and this has a great healing effect on their mind, body and soul.

The involvement of female elders $(17 \%)$ is higher than that of the male elders $(06 \%)$ in religious celebrations. The participation of females in these celebrations is quite impressive because these functions provide them 
plenty of opportunities for recreation. They relish this very much as most of the time life is rather dull for them. As there are more recreational possibilities available for men, their participation in Thiruvila celebrations is much less. A wide variety of food items is distributed free to everyone present during these functions. The female elders play an important part in organising the collection of food items, and their preparation. These types of celebrations though very popular in Muslim areas earlier, now seem to have lost importance due to the Islamic Renaissance, which frowns upon deviant practices perpetrated by ignorant adherents of Islam.

The study reveals that their wealth of experience enables elders to contribute much $(09.5 \%)$ towards the administration of religious institutions and to assume leadership roles. Elders are the guiding lights in the administration committees of religious institutions such as Mosque, Temple, Church and other religious organisations. Mosques and Temples in the study area have boards of administration in which elders are the predominant members. It is very rare $(01.3 \%)$ to find female members in these boards due to religious and cultural constraints.

There is a significant number of elders engaged in social work $(21.0 \%)$ who are connected to religious organizations. Giving financial help to affected women such as disaster victims and widows, organizing medical services, conducting awareness programs and being involved in youth empowerment activities are some of the services performed by elders affiliated with religious organizations. The elders also take on mediating activities when disputes arise among community members. Further, they provide counselling to the people by working from their respective religious institutions. They also organize Shramadana activities with the help of Mosque, Church and Temple trustees to clean the environment. This involves cleaning religious institutions, schools and even the cemetery in their areas. The elders voluntarily engage in community services organised by their religious institutions without expecting any payment for their work, their only expectation being to get rewards from God. The Zakath (alms-giving) collection in the Muslim community is carried out mainly by elderly volunteers. People tend to be averse to paying due Zakath on time. In these circumstances, the elders' persuasion prompts such people to pay the Zakath without undue delay. The elders are also involved in finding deserving people for the Zakath distribution. This way the elders not only serve the society but they also derive some satisfaction for their soul. Likewise, in Tamil areas active voluntary involvement of the elders helps to raise funds for building temples, orphanages etc. In the study area, it was observed that there were more male elders $(13 \%)$ than female elders $(08 \%)$ involved in social work.

Spiritual journey is mainly performed by the elders (14.0\%) to fulfil their religious obligation, personal vows and to attain soul satisfaction. For Muslims, going to Mecca to perform Hajj is a religious obligation while going to Mecca to perform Umrah and to visit other places of religious significance are optional acts. In addition, when a Muslim joins a religious organization to undertake some religious activity away from home, that too is considered as a spiritual journey. In the case of Tamil Hindus in the study area, a trip to Kataragama or other sacred place to fulfil a vow is also considered a spiritual journey. The Tamil Hindus believe that walking to Kataragama will not only provide merit from their God but it would also grant them good health. Equal numbers of male and female elders go on spiritual journeys.

The study reveals that $20 \%$ of elders visit the sick and pray for their quick recovery. Religious thoughts prompt the elders to visit sick people, disabled persons and orphans in their neighbourhood. The elders' involvement in this activity is highly appreciated by everyone in society. The mind and soul of the sick person becomes much lighter after the visit of an elder, as it does much to relieve his worries and loneliness. The elders not only visit the sick and disabled but also go to funeral houses, even to the cemetery, and they visit the bereaved relatives and console them as they suffer greatly due to the loss of a loved one. The elders use soft words and kindly manner when communicating with the sick and poor. This activity not only benefits the sick people but provides some comfort to their family members too. This activity strengthens the bonds of brotherhood and friendship between the elders and society. Figure 01 clearly illustrates the role of elders in religious activities, based on gender. 


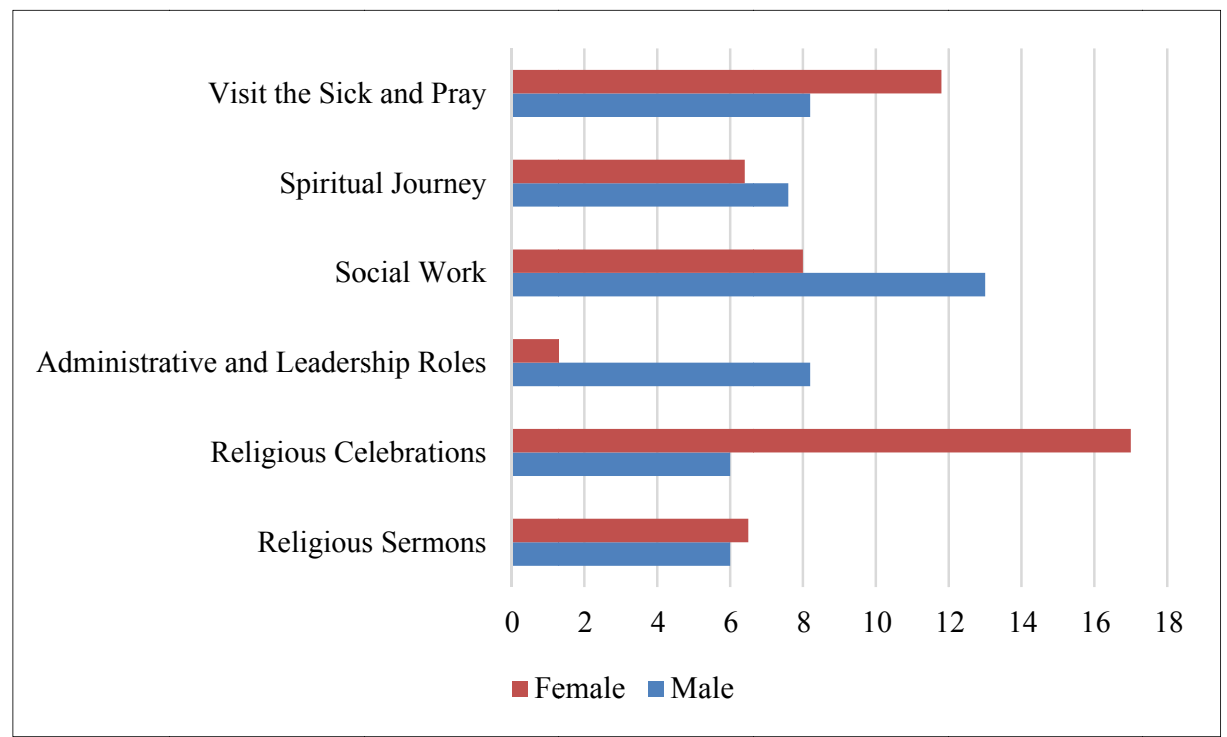

Figure 1. Role of elders in religious activities, based on gender

\subsection{Reasons for the High Level of Piousness among Elderly People}

The universal prevalence of religion among all peoples underlines the fact that religion possesses a great survival value. No power can abolish it. Religion is not solely comprised of beliefs and practices, it is also a social institution that performs different functions in the society (Rao, 2007). Religion has continued to be a central motif in all societies and it prescribes how individuals should behave and adjust to the surroundings in which they live. People seek to answer questions about the meaning of their existence through their religiosity and piousness. In this respect, the study discovered multiple reasons for the high level of piousness among the elderly people in the study area as compared to other age categories. Figure 02 clearly presents the reasons as follows.

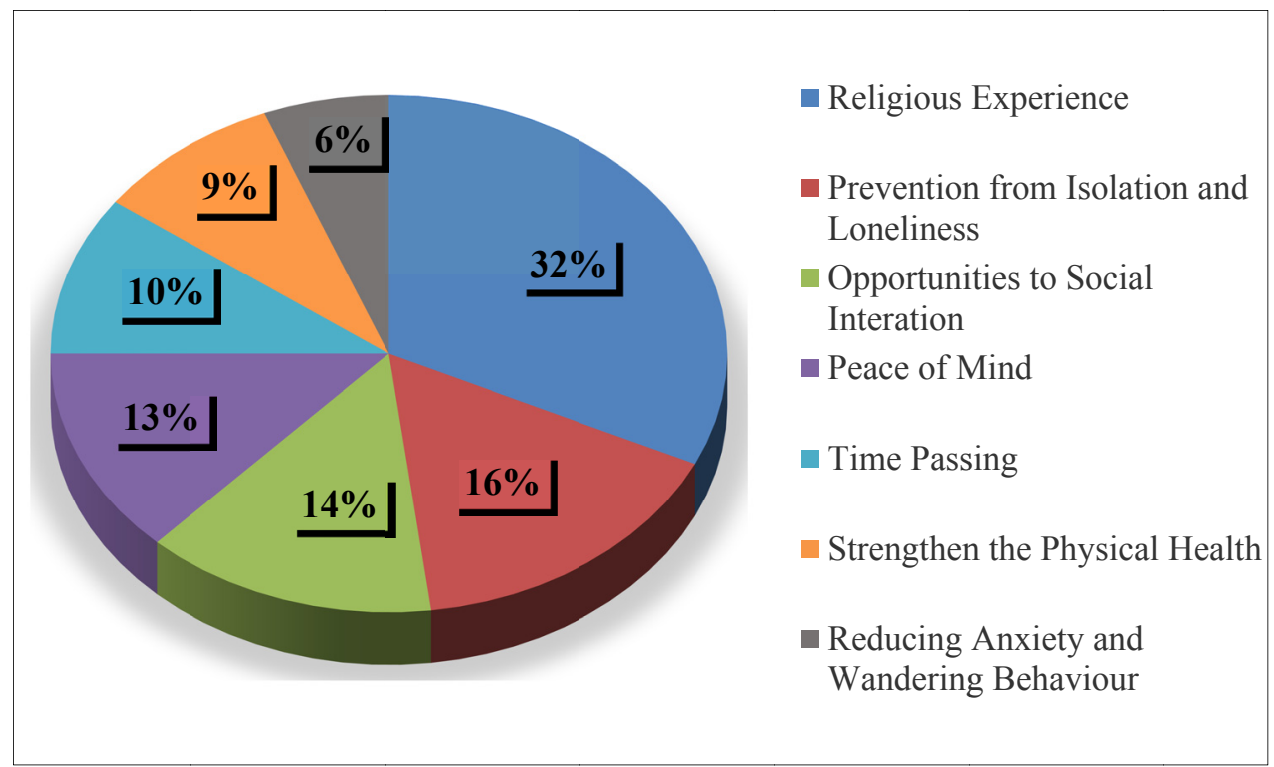

Figure 2. Reasons for the high level of piousness among elderly people

32 percent of the elders in the study area pointed out that piousness was a religious experience, which makes them appreciate the value of human existence. Generally, religious experiences involve prayer, worship and meditation. Majority of elders engage in religious practices to gain religious experience by expressing their respect, gratitude and faithfulness to their God or supernatural force. Muslims get this experience by worshiping God Allah, Hindus get this experience by worshiping God Siva, Vishnu and other deities, and Christians get this experience by awaiting the arrival of Jesus. The elders feel some sort of difficult-to-explain and unusual but 
emotionally elevating experience through their religious practices. Elders emphasize that they temporarily forget the worldly life and its problems when they engage in their religious observances. Moreover, this religiosity among the elders has the effect of enhancing their emotional maturity, which helps them to develop wisdom, persistence and confidence within themselves to continue with their life.

The final stage in the life of elderly people is usually filled with isolation and loneliness. Elders can feel loneliness and isolation not only when they live separately from their children and grandchildren, they can feel that way even while living with their family members under the same roof. This feeling of isolation is often felt after all their children are married and move out to start their own lives. The loneliness can also increase drastically if the spouse happens to pass away. Elderly persons can feel abandoned when facing such a situation and then they are overcome by feelings of isolation and loneliness during their last period of life. Such situations cause numerous negative impacts on people of all age categories, but the problem can be especially acute among elders. Emile Durkheim clearly pointed out that long-term isolation could eventually lead people to commit suicide. 16 percent of the elders stated that they engaged in religious activities, religious celebrations, administrative work, and social work like visiting sick people, etc. in order to escape from isolation and loneliness. Thus, the pious life helped them to keep loneliness at bay. The religious engagement provided a sense of emotional security and comfort to the elders by enabling them to interact with family members and neighbourhood, thereby making them feel that they were a part of the society.

14 percent of the people in the study area expressed the view that religion provides opportunities for social interaction among the people. The elderly people of the study area did have many opportunities to interact, communicate and keep in touch with other people through these religious activities. By delivering religious sermons, participating in religious celebrations, assuming leadership roles, going on spiritual journeys, visiting the sick and praying for them, elders can live and lead their lives in a more fulfilling manner. Elderly people also emphasised that they gradually forget their petty personal problems and eventually the problems vanish because of interacting with people in the society and devoting time to religious practices. The social interaction made possible through the pious lifestyle enabled the elderly people in the study area to resume many of their previous life activities, allowing them to lead a more normal life. This provided more opportunities to mingle with people from all walks of life without hesitation. Therefore, the desire for social interaction can be seen as another important reason that drives the elderly people to engage more in religious activities and lead a pious life.

Religion is believed to provide peace of mind to the believers who follow it. Religion is invoked to receive solace and peace of mind in respect of every problem faced by the people (Rao, 2007). In this regard, 13 percent of the elders claimed that the pious life provides them with the greatest peace of mind, which empowers them to deal with their ageing issues. These religious thoughts and engagement in religious activities benefit the elders because they tend to promote good qualities and help to develop a good character. Their life is filled with uncertainties, indefiniteness, dangers, risks, insecurities and unhappiness, causing them much distress. In this state of mind, an environment of religiosity and pious life can prove to be a great healer of worry, thus bringing peace of mind to the elders. This 13 percent of the elderly people pointed out that the pious life did reduce their grievances to some extent, which helped them to view every single act of the people surrounding them in a positive way. Religious engagement provides emotional and moral support to the elderly people to overcome their inner problems. Elderly people who were interviewed also mentioned that their pious life has become a beacon of hope that lights up their mind, thus making them feel at peace with the world and offering them much emotional consolation. This piousness reconciles the elders with any conflicts they may face and it supports them to establish values and goals for themselves. Moreover, the pious life of elderly people impresses on them the value of their existence in their old age too.

People of the modern society do not have a single minute of time to spend with family members or friends creatively. People are often bound to multiple tasks and feel pressed by obligations to be productive members of society. People of the industrial and post-industrial age find it very difficult to spend time with their elders when compared to people of the pre-industrial societies. The elderly population found that it had plenty of time on its hands after leaving work and going into retirement. This old age period presents too much free time to the elders in every society but most of them are at a complete loss as to what to do with this surfeit of time. 10 percent of the elders in the study area mentioned that they engage in religious activities to pass their free time effectively and usefully. Devoting time to religious activities helped them to overcome the laziness and boredom in their daily life and it willed them to feel more energetic, enabling them to cope better with real life situations and people.

The expectation that their physical health will improve is also considered as one of the reasons for the high level of piousness among elderly people in the study area. 09 percent of the respondents reported that they engaged in 
religious ceremonies because these gave them perfect satisfaction and a feeling of enhancement to their mind and body. Mostly, the elders in the study area engaged in social work and other activities to stimulate their body to keep it energetic. In addition, they reported that though the spiritual journeys the Muslims made to Mecca and the pilgrimages the Hindus made to Kataragama by walking are difficult tasks, the elders often engage in those activities to attain emotional satisfaction and to make them physically healthy. Based on the views of the elderly people, strengthening their physical health is also one of the reasons for their involvement in demanding religious rituals.

Previous researches on ageing populations pointed out that elders often get angry and emotionally weak in their old age. Some consider this point as baseless while others consider it as truthful to some extent. Generally, ageing brings out some odd kinds of behaviour in every human due to ageing issues. Anxiety is one of the emotional conditions that occur in all humans at every age, and it can be seen in old age too. At the same time, elderly people remain at home much of the time without having or doing any hard work due to their age. They often wander aimlessly here and there both mentally and physically to kill their time and loneliness. In this regard, 06 percent of the elderly population of the study mentioned that they engage in religious activities and spend more time on religious work to reduce their anxiety and wandering behaviour. Elders reported that they often feel anxiety if they sit alone without doing any work because their mind wanders with different thoughts. On the other hand, moving around the house aimlessly caused them boredom. In this situation, engaging in worship, prayers, reciting religious books, and giving religious advice to the family members and relatives has proved itself as a good solution to control their emotions and curtail their wandering and purposeless behaviour.

\section{Conclusion}

Disengagement theory emphasizes that the withdrawal from social interaction that occurs in old age is a natural and universal process. In marked contrast, the activity theory differs diametrically from the disengagement theory and posits that the older population is able to stay involved and active. The elders are active in the social sphere in the study area, particularly in religious activities, such as religious sermons and ceremonies. Their administrative and leadership roles are appreciable and help to run the non-profitable religious institutions smoothly. For the betterment and good functioning of the society, the elders involve themselves in social work organized by various religious institutions. The spiritual journey and experience of the elders provide them with the ways to attain soul satisfaction. The activity of visiting the sick and those afflicted with disease creates friendship and gives them the opportunity to avoid loneliness. There are many reasons for the high level of piousness among elderly people in the study area. Religious immersion prevents isolation and loneliness, presents opportunities for social interaction, offers peace of mind, helps to pass time, strengthens the physical health, and reduces anxiety and wandering behaviour. These are the major reasons for the high levels of piousness among elderly people.

\section{References}

Abeykoon, A. T. P. L., \& Ruwanthi, E. (2008). Emerging social issues of population ageing in Sri Lanka. Economic Review, 34, 07-09.

Amarabandu, W. P. (2004). Elderly population and social security in Sri Lanka. In Ageing population in Sri Lanka: Issues and future prospects (pp.77-122). Colombo, Sri Lanka: United Nation Population Fund (UNFPA) \& Population Association of Sri Lanka (PASL).

Chadha, N. K. (1997). Ageing and the Aged: Challenges before Indian Gerontology. Delhi: Friends Publications.

De Silva, Indralal., Kumudika, B., \& Manjula, R. (2008). Ageing population and social security in Sri Lanka. Economic Review, 34, 2-6.

De Silva, W. I., \& Samarasekara, D. (1999). Population ageing: Emerging issues in Sri Lanka. Economic Review, $34,12-15$.

District Secretariat. (2015). Annual Performance Report \& Accounts-2015. Ampara, Sri Lanka: District Secretariat.

District Secretariat. (2018). Annual Performance Report \& Accounts-2018. Ampara, Sri Lanka: District Secretariat.

Haralambos, M., \& Heald, R. M. (2004). Sociology: Themes and Perspectives. London: Harper Collins Publishers Limited.

Kaplan, D., \& Berkman, B. (2019, May 20). Religion and Spirituality in Older Adults. Retrieved from https://www.msdmanuals.com/professional/geriatrics/social-issues-in-older-adults/religion-and-spirituality-i 
n-older-adults

Nasreen, A. (2009).Urban elderly: Coping strategies and social responses. New Delhi: Concept Publishing Company.

Rao Sankar. (2002). Sociology: Primary Principles. New Delhi: S.Chand and Commpany Ltd.

Sanderatne, N. (2004). Socioeconomic Implications of ageing. In Ageing population in Sri Lanka: Issues and future prospects (pp. 204-224). Colombo, Sri Lanka: United Nation Population Fund (UNFPA) \& Population Association of Sri Lanka (PASL).

Seneviratne Rohini. (2004). Ageing and Health in Sri Lanka. In Ageing Population in Sri Lanka: Issues and Future Prospects (pp. 225-254). Colombo, Sri Lanka: United Nation Population Fund (UNFPA) \& Population Association of Sri Lanka (PASL).

Sharma, Y. K. (2007). Indian society: Issues and problems. Agra: Lakshmi: Narain Agarwal Publication.

Siddhisena, K. A. P. (2004). Demography of Ageing in Sri Lanka. In Ageing population in Sri Lanka: Issues and future prospects (pp.7-44). Colombo, Sri Lanka: United Nation Population Fund (UNFPA) \& Population Association of Sri Lanka (PASL).

Siddhisena, K. A. P. (2005, October). Socio-economic implications of ageing in Sri Lanka: An overview. Retrieved from https://pdfs.semanticscholar.org/afac/7bf7330eefea83da75447549e851a8307ba4.pdf

Siddhisena, K. A. P., \& Ratnayake, K. (1998) Ageing of population and elderly care in Sri Lanka. Sri Lanka Journal of Population Studies, 1(1), 35-55.

Silva, K. T. (2004). Elderly population, family support and intergenerational arrangements. In Ageing population in Sri Lanka: Issues and future prospects (pp.45-76). Colombo, Sri Lanka: United Nation Population Fund (UNFPA) \& Population Association of Sri Lanka (PASL).

Tarani, C. (2013). Ageing and the life course. In J. Gabe, \& L. F. Monaghan (Eds.), Key Concepts in medical Sociology (pp. 87-90). London: Sage Publications Ltd.

Thane P. (1989). History and the sociology of ageing. Social History of Medicine, 2(1), 93-96. https://doi.org/10.1093/shm/2.1.93

Tibittis, C. (1960). Handbook of social gerontology. Chicago: University of Chicago Press.

Wijeratne, S. S. (2004). Law and the Rights of the Elderly. In Ageing Population in Sri Lanka: Issues and Future Prospects (pp. 155-202). Colombo, Sri Lanka: United Nation Population Fund (UNFPA) \& Population Association of Sri Lanka (PASL).

Wijewantha, N. W. E. (2004). The Role of NGOs and Institutional Arrangements for the Ageing in Sri Lanka. In Ageing Population in Sri Lanka: Issues and Future Prospects (pp277-302). Colombo, Sri Lanka: United Nation Population Fund (UNFPA) \& Population Association of Sri Lanka (PASL).

\section{Copyrights}

Copyright for this article is retained by the author(s), with first publication rights granted to the journal.

This is an open-access article distributed under the terms and conditions of the Creative Commons Attribution license (http://creativecommons.org/licenses/by/4.0/). 